\title{
The Subliminal Mere Exposure Effect Does not Generalize to Structurally Related Stimuli
}

\author{
BEN R. NEWELL, University College London, UK \\ JAMES E. H. BRIGHT, University of New South Wales, Sydney, Australia
}

\begin{abstract}
R.F. Bornstein (1994) questioned whether subliminal mere exposure effects might generalize to structurally related stimuli, thereby providing evidence for the existence of implicit learning. Two experiments examined this claim using letter string stimuli constructed according to the rules of an artificial grammar. Experiment 1 demonstrated that brief, masked exposure to grammatical strings impaired recognition but failed to produce a mere exposure effect on novel structurally related strings seen at test. Experiment 2 replicated this result but also demonstrated that a reliable mere exposure effect could be obtained, provided the same grammatical strings were presented at test. The results suggest that the structural relationship between training and test items prevents the mere exposure effect when participants are unaware of the exposure status of stimuli, and therefore provide no evidence for the existence of implicit learning.
\end{abstract}

Are subliminal mere exposure effects a form of implicit learning? Bornstein (1994) posed this question in relation to the debate about the existence of dissociable implicit and explicit learning systems (see Shanks \& St. John, 1994a). He argued that if an experiment could demonstrate that: "subjects' responses to merely exposed subliminal stimuli generalise to other, similar stimuli that are encountered at some later date," we would be able to conclude that: "subliminal mere exposure effects fulfil the criteria required to demonstrate the existence of implicit learning effects" (1994, pp. 398-399). This paper presents two experiments that answer Bornstein's question.

The mere exposure effect is defined as an increase in positive affect, resulting from the repeated presentation of previously unfamiliar stimuli (Seamon, Brody, \& Kauff, 1983). It was first reported by Zajonc (1968) and has since been demonstrated in over 200 experiments involving a diverse range of stimuli (see Bornstein, 1989 for a review). A number of these studies have used subliminal stimuli to produce the increase in positive affect. Kunst-Wilson and Zajonc (1980) were the first to report a "subliminal mere exposure" effect - an increase in positive affect in the absence of awareness of the exposure status of the stimuli.

The subliminal mere exposure effect has been replicated many times with a variety of stimuli and appears to be robust and reliable (Bornstein, Leone, \& Galley, 1987; Mandler, Nakamura, \& Van Zandt, 1987; Seamon, McKenna, \& Binder, 1998; Seamon et al., 1983). It is an important finding because it demonstrates that an indirect measure of responding (one that makes no reference to a prior study/exposure episode: the preference test) can be more sensitive than a direct measure (one that does refer to a prior study/exposure episode: the recognition test) to information about recent encounters with a stimulus (St. John \& Shanks, 1997). The greater sensitivity of an indirect measure over a direct measure has been taken as strong evidence for the existence of implicit influences on performance (see Reingold \& Merikle, 1990 for a detailed discussion of this issue).

Several authors have suggested that exploring the relation between implicit learning and mere exposure may provide a way of understanding the nature of the processes underlying the two phenomena (e.g., Gordon \& Holyoak, 1983; Manza \& Bornstein, 1995; Manza, Zizak, \& Reber, 1998; Newell \& Bright, 2001). Studies have used a variation of the widely researched artificial grammar paradigm to investigate whether the increase in affect observed for identical stimuli, generalizes to similar structurally related stimuli. Participants are exposed to a series of consonant strings generated by a finite state grammar. These strings are termed "grammatical" because they conform to the rules of the grammar. Following exposure, participants provide liking ratings on a set of novel strings, half of which conform to the rules of the grammar (grammatical) and half of which do not (ungrammatical). The reliable finding is that participants give consistently higher liking ratings to novel grammatical strings than novel 


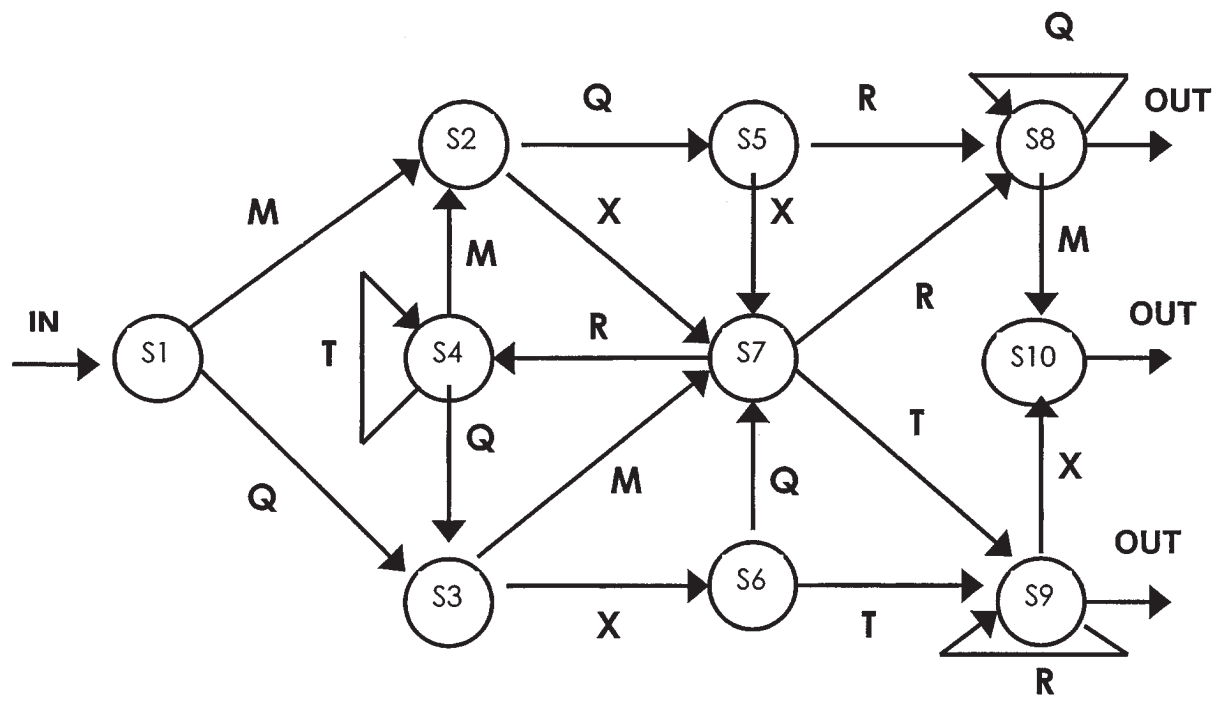

Figure 1. The artificial grammar (adapted from Vokey \& Brooks, 1992) used to generate all stimuli for Experiments 1 and 2 .

ungrammatical strings. This finding has been interpreted as evidence that the positive affect produced by exposure to a set of stimuli generalizes to previously unseen stimuli that are structurally related (i.e., follow the rules of a grammar) to the exposed stimuli (Gordon \& Holyoak, 1983; Manza \& Bornstein, 1995; Newell \& Bright, 2001).

The relevance of the subliminal mere exposure effect to the implicit/explicit learning debate is, quite simply, that if there is a source of information available for making a liking judgment that is not available for a recognition judgment, then this information might be the end product of an implicit learning system that operates alongside an explicit system (Shanks \& St. John, 1994b). The foregoing evidence confirms that mere exposure effects generalize to structurally related stimuli when the initial exposure is supraliminal. However, in addition to the increase in positive affect for grammatical stimuli, subjects in these studies can distinguish reliably between old (previously presented) and new grammatical strings (e.g., Manza \& Bornstein, 1995). This reliable recognition performance makes it unnecessary to appeal to implicit effects to explain the increase in affect. The tantalising question is whether subjects are able to discriminate grammatical from ungrammatical strings on an indirect measure (liking) when they are unable to discriminate old from new strings on a direct measure (recognition). To answer this question, a procedure used recently to obtain reliable supraliminal structural mere exposure effects was modified.

Newell and Bright (2001) reported that in three experiments participants exposed to grammatical strings during training gave novel grammatical strings reliably higher liking ratings than ungrammatical strings - a "structural mere exposure effect" (cf. Manza et al., 1999). In these experiments, each string was presented during training for 5 seconds - a duration known to be sufficient for reliable discrimination between old and new grammatical strings (Manza \& Bornstein, 1995). The crucial procedural differences between these previous experiments and Experiment 1 was to reduce the presentation duration from 5 seconds to 100 milliseconds and to display a pattern mask after the presentation of each string. These alterations were made in an attempt to ensure that the presentations were "subliminal" or at least "suboptimal" (Murphy, Monahan, \& Zajonc, 1995). All other aspects of the materials and procedure were identical.

We reasoned that if participants gave novel grammatical strings higher liking ratings than ungrammatical strings, while simultaneously being unable to distinguish old grammatical from new grammatical strings in a recognition test, this would constitute evidence for a "subliminal" structural mere exposure effect (e.g., Bornstein, 1994).

\section{Experiment 1}

METHOD

Thirty undergraduate students from the University of New South Wales were exposed to letter strings generated from a finite state grammar and then rated strings in liking and recognition tests.

Strings of three to seven letters in length made up of the letters $\mathrm{M}, \mathrm{Q}, \mathrm{R}, \mathrm{X}$, and $\mathrm{T}$ were generated from the grammar shown in Figure 1 (adapted from Vokey \& 
TABLE 1

Mean Rating and Standard Error of the Mean of Items as a Function of New / Old and Grammaticality Status.

\begin{tabular}{|c|c|c|c|c|c|c|c|c|}
\hline \multirow{3}{*}{$\frac{\text { Task }}{\text { Item }}$} & \multicolumn{4}{|c|}{ Recognition } & \multicolumn{4}{|c|}{ Liking } \\
\hline & \multicolumn{2}{|c|}{ New } & \multicolumn{2}{|c|}{ Old } & \multicolumn{2}{|c|}{ G } & \multicolumn{2}{|c|}{ UG } \\
\hline & $M$ & $S E$ & $M$ & $S E$ & $M$ & $S E$ & $M$ & $S E$ \\
\hline & 3.51 & 0.07 & 3.49 & 0.07 & 3.34 & 0.10 & 3.33 & 0.09 \\
\hline
\end{tabular}

Note: $\mathrm{G}=$ grammatical, $\mathrm{UG}=$ ungrammatical

Brooks, 1992). In such a grammar, there are a finite number of states (the circles) and a specified route of transitions through these states (the arrows). Strings are generated by entering the grammar at S1 and following the arrows through the network, picking up letters at each state. The network can then be exited at S8, 9, or 10. Strings generated in this way are termed grammatical, (e.g., MXRQXT, QXQRQM, and MQXTR). If the route of transitions is not followed correctly, the resulting strings contain violations of the grammar. These strings are termed ungrammatical, (e.g. MXRRXT, MXRTQMM, and TXTRRX). (See the Appendix for a list of all the strings used in the two experiments.)

The exposure set consisted of 16 items that followed the rules of the grammar (grammatical strings). The liking set consisted of 32 novel grammatical strings and 32 novel strings that violated the rules of the grammar (ungrammatical strings). Consistent with previous research (Vokey \& Brooks, 1992; Manza \& Bornstein, 1995), ungrammatical items contained at least one letter in a position that is not permitted by the rules of the grammar. The recognition set comprised the 16 original exposure items and a further 16 novel grammatical items. No item was present in both the recognition and the liking set.

Each stimulus display in the presentation phase consisted of three components: a black fixation cross, a letter string, and a pattern mask all presented against a white background. The fixation cross was presented centrally and measured $2 \mathrm{~cm}$. It remained on screen for 2,000-ms. The item then appeared in the same central location. Strings were presented in Black Arial font size 16 and remained on screen for 100-ms. A string was immediately replaced by a pattern mask (\#\#\#\#\#\#) for a duration of 100-ms. Finally, the screen went blank (white) for a 1,000-ms post-trial pause.

At the start of the experiment, participants were led to believe that they were participating in a study concerned with visual perception. Participants sat in a normally lit room at a viewing distance of approximately $40 \mathrm{~cm}$ from the computer screen. They were told that they would see strings made up of the letters M, Q, R, $\mathrm{T}$, and $\mathrm{X}$ flashed briefly on the screen. They were told to attend to these strings as best they could for the duration of the presentations. In-between presentations, they were told to fixate on the cross in the centre of the screen because this was where the next string would appear. At this stage no mention was made of the subsequent test phases. The 16 exposure strings were shown in five blocks with a different random order of presentation within each block for a total of 80 presentations.

Following exposure, about half the participants made recognition judgments ("have you seen this string before?") on a scale ranging from 1 ("I'm REALLY SURE this string is NEW") to 6 ("I'm REALLY SURE this string is OLD") on the 32 recognition set strings, and then made liking ratings ("How much do you like this string?") on a similar scale, 1 ("I REALLY DON"T LIKE this string"), 6 ("I REALLY LIKE this string") on the liking set strings. For the other participants, the order of judgments was reversed. Finally, participants were asked to write down any information relating to how they made their decisions in the recognition and liking tasks.

\section{RESULTS AND DISCUSSION}

There were no effects for the order in which the preference and recognition judgments were made, $F(1,28)=$ $.30, p>.5$, so the ratings from both orders were combined for analysis. Table 1 shows the mean ratings and standard errors for the new and old strings in the recognition task and the grammatical and ungrammatical strings in the liking task.

There were no reliable differences between the ratings of grammatical and ungrammatical strings in the liking task, $t(29)=.38, p>.5 ; 95 \% \mathrm{CI}=-.075, .110$, or between the ratings given to new and old strings in the recognition task, $t(29)=.39, p>.5 ; 95 \% \mathrm{CI}=-.15, .10$. The results of the recognition test indicate that the 100-ms exposure duration was sufficient to eliminate participants' ability to distinguish old from new grammatical strings. However, making participants unaware of the exposure status of the stimuli also appeared to eliminate the structural mere exposure effect - an effect previously found using longer exposure durations (e.g., Gordon \& Holyoak, 1983; Manza \& Bornstein, 1995; Newell \& Bright, 2001). The results suggest that, contrary to Bornstein's (1994) conjecture, "subliminal" mere exposure effects do not generalize to structurally related material. 


\section{Experiment 2}

One problem in interpreting the absence of effects in both the recognition and the liking tasks of Experiment 1 is that it is possible that the training exposures failed to influence participants at all. In order to be able to conclude that it is the structural relationship between training and test items that prevents the mere exposure effect, a demonstration is required that a mere exposure effect can be obtained under suboptimal presentation conditions, provided the same strings are presented in test as in training. A further possibility for the null effects is the insensitivity of the rating scales to the small liking effect that might be expected (cf. Kunimoto, Miller, \& Pashler, 2001).

To examine these two issues, Experiment $2 \mathrm{com}-$ pared the performance of participants given more sensitive two alternative forced-choice (2-AFC) liking decisions on either paired old grammatical (i.e., seen during the exposure phase) and ungrammatical strings, or paired novel grammatical (i.e., structurally related) and ungrammatical strings. If old grammatical strings are selected at a rate significantly above chance and novel grammatical strings are not, this would constitute strong evidence that is the structural relationship between training and test strings that prevents the mere exposure effect obtaining under 100-ms exposure conditions.

\section{METHOD}

Thirty undergraduate and postgraduate students from University College London were exposed to the same exposure set, under the same conditions as Experiment 1. Half of the participants then made 2-AFC liking decisions ("Choose the string you like more") on paired old grammatical strings and ungrammatical strings. Each of the 16 grammatical strings seen during exposure was paired twice at random with each of the 32 ungrammatical strings, resulting in 32 pairs. The other half of the participants made the same judgments on the liking set strings used in Experiment 1 (i.e., paired novel grammatical and ungrammatical strings).

\section{RESULTS AND DISCUSSION}

The mean percentage of old grammatical strings selected was $57.0 \%(S E=2.58)$ and the mean selection of novel grammatical strings was $51.3 \%(S E=2.06)$. These means were significantly different from each other, $t(28)=1.78, p<.05$; one tailed. More importantly, selection of old grammatical strings was above that of chance (50\%), $t(14)=3.06, p<.01 ; 95 \% \mathrm{CI}=52.0$, 61.7, whereas selection of novel grammatical strings was not, $t(14)=.610, p>.50 ; 95 \% \mathrm{CI}=46.7,55.9$. Note that the mean for the selection of old strings (57.0\%) lies outside the upper limit of the $95 \%$ confi- dence interval for the novel strings (55.9\%), strengthening the conclusion that the difference in string selection between the conditions is a real effect. However, we acknowledge that the upper limit of $55.9 \%$ precludes us from ruling out the possibility that a small but above chance effect (i.e., $54 \%$ or $55 \%$ ) may exist for the novel strings.

The results demonstrate that when the same grammatical strings are presented at training and test a reliable mere exposure effect can be obtained under $100-\mathrm{ms}$ presentation conditions. However, presenting structurally related strings eliminates the mere exposure effect. This demonstration strongly suggests that it is the structural relationship between the training and test strings that prevents the mere exposure effect. Examination of individual data also supports this interpretation. For the old grammatical versus ungrammatical group, $80 \%$ of participants showed a mere exposure effect (i.e., their selection of old strings exceeded 50\%). In contrast, for the novel grammatical versus ungrammatical group, only $40 \%$ of participants showed an effect.

To facilitate comparison of the results of Experiment 1 with those of Experiment 2, we converted the ratings data to $a^{\prime}$, as there is good reason to believe that $a^{\prime}$ is comparable to forced-choice performance (Green \& Swets, 1974). For the liking task, grammatical strings given a rating of 4,5 , or 6 (i.e., liked) were classified as a bit and those rated 1, 2, or 3 (i.e., not liked) as a false alarm. Ungrammatical strings given a rating of 4,5 , or 6 were classified as a miss and those rated 1,2, or 3 as correct rejections. The same conversion procedure was used for the recognition task ratings.

The mean $a^{\prime}$ for the liking task was $47.4 \%(S E=1.6)$, which is comparable to the $51.3 \%$ found with the same materials using the forced-choice procedure in Experiment 2 . This $a^{\prime}$ value was not significantly different from chance $(50 \%), t(29)=1.51, p>.1 ; 95 \% \mathrm{CI}=$ $44.0,50.9$. For the recognition task, the mean $a^{\prime}$ was $49.3 \%(S E=2.5 \%)$ and, again, was not significantly different from chance, $t(29)=.273, p>.5 ; 95 \% \mathrm{CI}=44.0$, 54.7. Analyses of the $a^{\prime}$ data confirm the pattern found with the raw ratings data and suggest that we would have found a similar pattern of results had we used a forced-choice procedure in Experiment 1.

\section{General Discussion}

The research presented here suggests that structural mere exposure effects cannot be obtained under conditions where participants are unaware of the exposure status of the stimuli. The results answer Bornstein's (1994) question: Subliminal mere exposure effects do not generalize to similar stimuli and therefore do not fulfil the criteria required to demonstrate the existence 
of implicit learning. It is possible that some other types of stimuli might show generalization (perhaps those in which there is a generalization of surface structure rather than underlying grammatical rules - see Seamon \& Delgado, 1999), thus our results do not unequivocally rule out a role for implicit responding in the mere exposure effect. However, the results do provide clear evidence that a structural mere exposure effect, which can be obtained when participants are aware of the presentation status of the stimuli (e.g., Gordon \& Holyoak, 1983; Manza \& Bornstein, 1995; Newell \& Bright, 2001), disappears when they are unaware of this status.

In studies of subliminal mere exposure, there is always discussion as to whether or not presentations were actually subliminal (e.g., Murphy et al., 1995). Presentation durations of $100-\mathrm{ms}$ are not consonant with the very brief duration (1 or $5 \mathrm{~ms}$ ), used in some previous studies (Bornstein et al., 1987; Kunst-Wilson \& Zajonc, 1980). However, the results of the recognition test in Experiment 1 suggest that it was sufficiently suboptimal to eliminate awareness of the exposure status of the stimuli (i.e., seen before or not?).

A further consideration is the possibility that if the same strings had been used in the liking and the recognition task (i.e., a false recognition test on novel grammatical and ungrammatical strings) participants may have been able to discriminate grammatical from ungrammatical strings. This is an empirical question, but even if such a pattern had been found, according to Bornstein and D'Agostino (1992) our exposure conditions would still have been "subliminal" in the sense that they use the term. They suggest that the critical aspect of subliminality may be the subjects' lack of awareness or understanding about the relationship between the initial exposure and the subsequent test. Under such an interpretation our exposure conditions can be argued to have been a test of "subliminal" processing as post-test questionnaires revealed no evidence to suggest that subjects understood the nature of the relationship between the exposure phase and the liking test.

Bornstein $(1992,1994)$ has argued that the existence of subliminal mere exposure effects provides evidence for the operation of an implicit system. However, Whittlesea and Price (2001) have argued that finding a dissociation between liking and recognition judgments does not mean that subjects are accessing qualitatively different forms of information, or that functionally distinct systems are in operation. They suggest that the dissociation implies simply that subjects engage in different styles of processing when performing the recognition and liking tasks. Liking judgments encourage a nonanalytical style of processing, which rely on fluen- cy-sponsored global feelings of familiarity. In contrast, recognition judgments invite analytical processing that requires specific local feature information. The initial exposure to training stimuli is so brief that subjects are unable to encode specific feature information, thus performance in the recognition test is poor. Liking judgments, by comparison, are performed successfully because even a brief exposure is sufficient for subjects to encode the global similarity information necessary to induce a feeling of familiarity when an old stimulus is encountered.

The current results can be readily incorporated into this analytic/nonanalytic framework by adding the important caveat that liking judgments will only be performed successfully following brief exposures if the same items are presented at training and test. Brief exposures to structurally related stimuli appear to be insufficient to induce feelings of familiarity.

The support of the Economic and Social Research Council (ESRC) and The Commonwealth Scholarship and Fellowship Fund is gratefully acknowledged. We thank Bruce Whittlesea, John Seamon, Michael Masson, Richard Tunney, and David Shanks for their helpful comments on the manuscript. Address correspondence to Ben Newell, Department of Psychology, University College London, Gower Street, London, WC1E 6BT (E-mail: b.newell@ucl.ac.uk).

\section{References}

Bornstein, R. F. (1992). Subliminal mere exposure effects. In R. F. Bornstein \& T. S. Pittman (Eds.), Perception without awareness: Cognitive, clinical and social perspectives (pp. 191-210). New York: Guilford Press.

Bornstein, R. F. (1994). Are subliminal mere exposure effects a form of implicit learning? Behavioral and Brain Sciences (17), 398-399.

Bornstein, R. F., Leone, D. R., \& Galley, D. J. (1987). The generalizability of subliminal mere exposure effects: Influence of stimuli perceived without awareness on social behavior. Journal of Personality and Social Psychology, 53, 1070-1079.

Brooks, L. R., \& Vokey, J. R. (1991). Abstract analogies and abstracted grammars: Comments on Reber (1989) and Mathews et al. (1989). Journal of Experimental Psychology General, 120, 316-323.

Gordon, P. C., \& Holyoak, K. J. (1983). Implicit learning and generalization of the mere exposure effect. Journal of Personality and Social Psychology, 45, 492-500.

Green, D. M. \& Swets, J. A. (1974). Signal detection theory and psychophysics. Oxford, UK: Robert E. Krieger.

Kunimoto, C., Miller, J., \& Pashler, H. (2001). Confidence and accuracy of near-threshold discrimination responses. Consciousness and Cognition, 10, 294-340. 
Kunst-Wilson, W. R., \& Zajonc, R. B. (1980). Affective discrimination of stimuli that cannot be recognised. Science, 207, 557-558.

Mandler, G., Nakamura, Y., \& Van Zandt, B. J. S. (1987). Nonspecific effects of stimuli that cannot be recognized. Journal of Experimental Psychology: Learning, Memory and Cognition, 13, 646-648.

Manza, L., \& Bornstein, R. F. (1995). Affective discrimination and the implicit learning process. Consciousness and Cognition, 4, 399-409.

Manza, L., Hallman, C., McCoy, A., Shumway, E., Ruchzak, M., Laepple, K., \& Dangler, R. (1999). Structural mere exposure: The influence of instructional set and stimulus complexity on implicit learning. Paper presented at the Eastern Psychological Association, Providence, RI.

Manza, L., Zizak, D., \& Reber, A. S. (1998). Artificial grammar learning and the mere exposure effect: Emotional preference tasks and the implicit learning process. In M. A. Stadler \& P. A. Frensch (Eds.), Handbook of implicit learning (pp. 201-222). Thousand Oaks, CA: Sage.

Murphy, S. T., Monahan, J. L., \& Zajonc, R. B. (1995). Additivity of nonconscious affect: Combined effects of priming and exposure. Journal of Personality and Social Psychology, 69, 589-602.

Newell, B. R., \& Bright, J. E. H. (2001). The relationship between the structural mere exposure effect and the implicit learning process. Quarterly Journal of Experimental Psychology, 54A, 1087-1104.

Reingold, E. M., \& Merikle, P. M. (1990). On the inter-relatedness of theory and measurement in the study of unconscious processes. Mind and Language, 5, 9-28.

Seamon, J. G., Brody, N., \& Kauff, D. M. (1983). Affective discrimination of stimuli that are not recognized: II.
Effect of delay between study and test. Journal of Experimental Psychology: Learning, Memory and Cognition, 9, 544-555.

Seamon, J. G., \& Delgado, M. R. (1999). Recognition memory and affective preference for depth rotated solid objects: Part-based structural descriptions may underlie the mere-exposure effect. Visual Cognition, 6, 145-164.

Seamon, J. G., McKenna, P. A., \& Binder, N. (1998). The mere exposure effect is differentially sensitive to different judgment tasks. Consciousness and Cognition, 7, 85102.

Shanks, D. R., \& St. John, M. F. (1994a). Characteristics of dissociable human learning systems. Behavioral and Brain Sciences, 17, 367-447.

Shanks, D. R., \& St. John, M. F. (1994b). How should implicit learning be characterized? Behavioral and Brain Sciences, 17, 427-447.

St. John, M. F., \& Shanks, D. R. (1997). Implicit learning from an information processing standpoint. In D. C. Berry (Ed.), How implicit is implicit learning? (pp. 162194). Oxford: Oxford University Press.

Vokey, J. R., \& Brooks, L. R. (1992). Salience of item knowledge in learning artificial grammars. Journal of Experimental Psychology: Learning, Memory and Cognition, 18, 328-344.

Whittlesea, B. W. A., \& Price, J. R. (2001). Implicit/explicit memory versus analytic/nonanalytic processing: Rethinking the mere-exposure effect. Memory \& Cognition, 29, 234-246.

Zajonc, R. B. (1968). Attitudinal effects of mere exposure. Journal of Personality and Social Psychology Monographs, 9, 1-27.

\section{APPENDIX}

Stimuli used for the recognition test in Experiment 1
OLD
MXRQXT
QMTRRRR
QXTRRR
QXQRMXT
QXQRQM
QMRQQQQ
MXRTMQR
QMRMXTR
MXR
QMRQXQR
MQRQM
QMRMQRQ
QMRMQXR
MXRTQXT
MXRMQXR
MQXTR
NEW
MQXRM
MQXRMQR
QXQT
MXRMXRQ
MXRTQMT
QMT
MQXRQMR
MQXRQQQ
MXRMXRM
QMRQMT
MXRQQQM
QXQRMXR
MXTRRRX
QXQTRRX
MXTRRX
QMRTMXT 
Stimuli used for the liking test in Experiment 1 and 2

\begin{tabular}{ll} 
GRAMMATICAL & UNGRAMMATICAL \\
MXRMXT & MXRRXT \\
QMTRRRX & QMTRRRT \\
QXTRRR & TXTRRR \\
QXQRQXT & QXQRTXT \\
QXQRQQ & QXQRQT \\
QMRQQQM & QMRQQQR \\
MXRTMXR & MXRTMTR \\
QMRQXTR & QMRTXTR \\
MQR & MTR \\
QMRQXQT & QMRQXQX \\
MXRQM & MTRQM \\
QMRMXRQ & QMRMTRQ \\
QMRMQXT & QMRMQXX \\
MXRTMXT & MXRTRXT \\
MXRMQXT & MXRMQXX \\
MQXTX & MQXTT \\
MQXRQ & MQXRT \\
MQXRMXR & MQXRMTR \\
QXQR & QXQM \\
MXRMQRQ & MXRMTRQ \\
MXRTQMR & MXRTQMM \\
QMR & QMM \\
MQXRQMT & MQXRQMX \\
MQXRQQM & MQXRQQR \\
MXRMQRM & MXRMTRM \\
QMRQMR & QMRQMM \\
MQRQQQM & MTRQQQM \\
QXQRMQR & QXQRMTR \\
QXTRRRX & TXTRRRX \\
QXQTRRR & QXQTRRM \\
QXTRRX & TXTRRRX \\
QMRTQXT & QMRTTXT \\
\hline &
\end{tabular}

\section{Sommaire}

R.F. Bornstein (1994) s'est demandé si les effets de la simple exposition subliminale pouvaient s'appliquer à des stimuli apparentés sur le plan structurel, et ainsi, fournir la preuve de l'existence de l'apprentissage implicite. L'effet de la simple exposition est défini comme l'augmentation d'un affect positif, causée par la présentation répétée de stimuli autrefois non familiers. Des recherches antérieures confirment que l'effet de la simple exposition peut s'appliquer aux stimuli apparentés sur le plan structurel, lorsque l'exposition initiale est supraliminaire (Gordon \& Holyoak, 1983; Manza \& Bornstein, 1995; Newell \& Bright, 2001). Cependant, en plus de l'augmentation de l'affect positif dans le cas des stimuli apparentés sur le plan structurel, les sujets ayant participé à ces études sont en mesure de faire de façon fiable la distinction entre les anciens stimuli (ceux présentés antérieurement) et les nouveaux stimuli (p. ex., Manza \& Bornstein, 1995). Cette performance fiable de la reconnaissance rend caduque la nécessité de faire appel aux effets implicites pour expliquer l'augmentation relative à l'affect. La question alléchante qui se pose maintenant : les sujets sont-ils capables de faire la différence entre les stimuli apparentés sur le plan structurel et les stimuli non apparentés selon une mesure indirecte (préférence), lorsqu'ils sont incapables de faire la différence entre des stimuli anciens et nouveaux selon une mesure directe (reconnaissance).

Deux expériences, qui ont eu recours à des stimuli composés de séries de lettres construites selon des règles de grammaire artificielles, ont été menées afin d'examiner cette question. L'expérience 1 a démontré qu'une exposition brève et masquée aux séries gram- 
maticales perturbait la reconnaissance, mais ne parvenait pas à produire l'effet de simple exposition aux nouvelles séries de lettres apparentées sur le plan grammatical observé pendant le test. L'expérience 2 reproduisait le même résultat mais démontrait également qu'un effet faible de la simple exposition pouvait être obtenu, à condition que les mêmes séries grammaticales soient présentées pendant le test. Les résultats laissent croire que la relation structurelle entre la formation et les items du test empêche l'effet de simple exposition lorsque les participants ne connaissent pas l'état de l'exposition aux stimuli, et par conséquent, ne fournissent aucune preuve de l'existence de l'apprentissage implicite.

Les résultats sont expliqués sous l'angle du cadre analytique/non analytique proposé par Whittlesea et Price (2001). Les jugements de préférence sont censés favoriser le style de traitement non analytique, qui repose sur les sentiments globaux de familiarité gouvernés par la fluidité. En revanche, les jugements de reconnaissance favorisent le traitement analytique qui exige de l'information particulière sur les caractéristiques locales. Lorsque l'exposition initiale aux stimuli présentés pendant l'entraînement est très brève, les participants sont incapables d'encoder l'information particulière sur les caractéristiques; la performance au test de reconnaissance est, par conséquent, faible. Les jugements de préférence sont, en comparaison, effectués avec succès car même une exposition brève est suffisante aux participants pour encoder l'information relative à la similarité globale requise pour entraîner un sentiment de familiarité lorsqu'un ancien stimulus se présente.

Les présents résultats suggèrent une mise en garde importante selon laquelle les jugements de préférence ne sont effectués avec succès à la suite d'expositions brèves que si les mêmes items sont présentés pendant l'entraînement et pendant le test. Les expositions brèves à des stimuli apparentés sur le plan structurel semblent insuffisantes pour entraîner des sentiments de familiarité. 